\title{
Operations research to improve postabortion (PAC) services in three public hospitals, Bolivia
}

Fernando Gonzales Salguero

Population Council

Mariel Loayza

Follow this and additional works at: https://knowledgecommons.popcouncil.org/departments_sbsr-rh

Part of the Demography, Population, and Ecology Commons, Health Services Research Commons, and the International Public Health Commons

How does access to this work benefit you? Let us know!

\section{Recommended Citation}

Gonzales Salguero, Fernando and Mariel Loayza. 2005. "Operations research to improve postabortion (PAC) services in three public hospitals, Bolivia," FRONTIERS Final Report. Washington, DC: Population Council. 


\section{Operations Research to Improve Postabortion Care (PAC) Services in Three Public Hospitals, Bolivia}

\section{Fernando Gonzáles and Máriel Loayza}

The Population Council, Bolivia

In collaboration with Pathfinder International, Bolivia

And the CATALYST Consortium, Washington, DC

March 2005

This study was funded by the U.S. AGENCY FOR INTERNATIONAL DEVELOPMENT (USAID) under the terms of Cooperative Agreement Number HRNA-00-98-00012-00 and Population Council In-house Project number 8000 13063. The opinions expressed herein are those of the author and do not necessarily reflect the views of USAID. 


\section{CONTENTS}

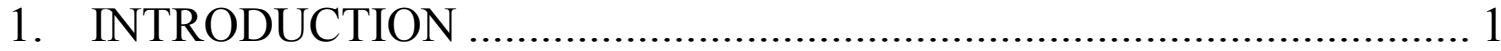

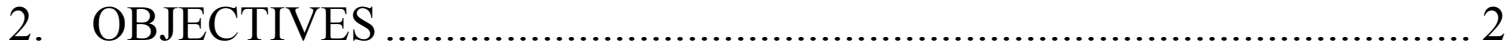

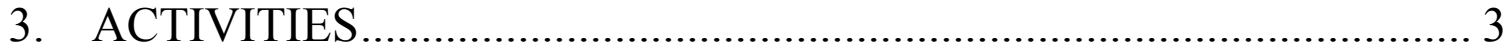

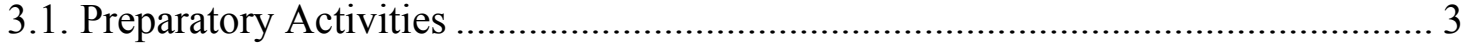

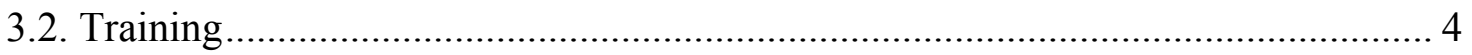

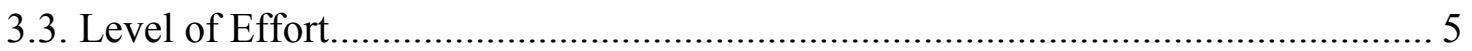

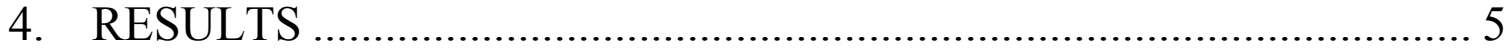

Hospital Materno Infantil Germán Urquidi, Cochabamba …………………………..... 5

Hospital Alfonso Gumucio Reyes, Montero............................................................... 7

Hospital Universitario Percy Boland, Santa Cruz............................................................ 8

5. DISSEMINATION AND UTILIZATION ......................................... 9

6. CONCLUSIONS AND RECOMMENDATIONS ….......................... 10

\section{APPENDICES}

APPENDIX 1. Maternal-child Hospital Germán Urquidi, Cochabamba. Spanish Language Final Report

APPENDIX 2. Alfonso Gumucio Reyes Hospital, Montero. Spanish Language Final Report

APPENDIX 3. Percy Boland University Hospital, Santa Cruz. Spanish Language Final Report

APPENDIX 4. Workshop Agendas 


\section{INTRODUCTION}

In the last five years, Pathfinder Bolivia has provided technical assistance, training and equipment to the Ministry of Health $(\mathrm{MOH})$ to implement postabortion care (PAC) services in eight hospitals. Pathfinder and the USAID Mission in Bolivia consider operations research (OR) an important tool to help solve existing service delivery problems. Therefore, they invited Frontiers in Reproductive Health (FRONTIERS) to collaborate in a project whereby participating $\mathrm{MOH}$ hospitals would implement the research and service delivery components, Pathfinder would contribute technical assistance and training for implementing the interventions, and FRONTIERS would provide the technical assistance and training for conducting the research activities.

This final report describes the second stage of this collaborative effort with the Bolivian office of Pathfinder International, the Catalyst Project, and the MOH. In the first stage, begun in 2002, the institutions conducted a study in eight hospitals to assess the effects of peer-review on quality improvement of PAC services ${ }^{1}$. The results of this study were presented in a three-day workshop attended by providers and staff members of the participant hospitals. During the workshop, participants also received OR training and developed draft OR proposals seeking to improve PAC service delivery problems identified during this first study. The four best draft proposals were selected and in the following months, FRONTIERS continued to provide technical assistance to the hospital provider teams, first to develop full OR proposals and later to implement the OR projects. Table 1 lists the project proposals developed.

\footnotetext{
${ }^{1}$ See Gonzales, Fernando and Patricia Riveros. 2003. Technical Assistance to Pathfinder to Conduct Operations Research on Postabortion Care. Operations Research Final Report, Frontiers in Reproductive Health, November; and Hernández, Orlando; Franz Calan, José del Barco, Patricia Riveros, Fernando Gonzáles, Cecilia Cossio and Claudia de la Quintana. 2003. Peer observation as a technique to train providers in the management of hemorrhagic complications in the first half of pregnancy within the framework of the post-abortion care program. Catalyst and Frontiers in Reproductive Health, La Paz, Bolivia, December.
} 
Table 1

Operations Research Project Proposals Developed by Participant Hospitals

\begin{tabular}{|l|l|}
\hline Hospital & Study \\
\hline Hospital Corea, El Alto, La Paz & $\begin{array}{l}\text { Incorporating the male partner into } \\
\text { counseling sessions to decrease unmet } \\
\text { need for postabortion contraceptive methods } \\
\text { in the Hospital Modelo Municipal Corea in } \\
\text { the city of El Alto }\end{array}$ \\
\hline $\begin{array}{l}\text { Hospital Materno Infantil Germán } \\
\text { Urquidi, Cochabamba }\end{array}$ & $\begin{array}{l}\text { Linking emergency postabortion care to } \\
\text { other outpatient sexual and reproductive } \\
\text { health services }\end{array}$ \\
\hline $\begin{array}{l}\text { Hospital Alfonso Gumucio Reyes, } \\
\text { Montero }\end{array}$ & $\begin{array}{l}\text { Linking PAC emergency care and other } \\
\text { sexual and reproductive health outpatient } \\
\text { services }\end{array}$ \\
\hline $\begin{array}{l}\text { Hospital Universitario Percy Boland, } \\
\text { Santa Cruz }\end{array}$ & $\begin{array}{l}\text { Evaluating a training strategy to diminish } \\
\text { unmet need for postabortion contraception }\end{array}$ \\
\hline
\end{tabular}

Although the Corea Hospital in El Alto developed a proposal, the operations research itself was not conducted because project staff felt their workload was too heavy to add new responsibilities and they were not given time off from their regular activities to coordinate and implement the OR activities. For this reason, the projects were conducted only in the Maternal-Child Hospital Germán Urquidi in Cochabamba, the Alfonso Gumucio Reyes Hospital in the city of Montero, and the University Maternity Percy Boland in Santa Cruz.

\section{OBJECTIVES}

This project's objective was to provide technical assistance to teams of providers in four public hospitals to develop and implement operations research projects seeking to find solutions to problems identified during the previous OR study they had conducted.

The expected results were:

- Operations research is implemented in four public hospitals in Bolivia.

- At least 4 hospital provider teams develop skills to prepare project proposals and implement OR studies.

- Successful strategies tested in participating hospitals are institutionalized.

As mentioned above, although the study team proposed to work in four hospitals, we were able to do so in only three, since an agreement could not be reached with the fourth hospital. As explained in the following sections, two and four providers were trained in each of the remaining hospitals. However, based on their background and the limited time available, the teams required constant technical assistance, particularly to complete the projects and write the reports. Two of the three interventions tested have been 
institutionalized. In the case of the Montero Hospital, the internal referral card is now being used for other hospital services, such as the postpartum ward.

\section{ACTIVITIES}

\subsection{Preparatory Activities}

Review of research proposals: FRONTIERS staff conducted several meetings with teams from the four hospitals to discuss their preliminary proposals, help them develop clear problem statements and develop the intervention strategies. The staff and directors of the participating hospitals, the FRONTIERS regional director and Pathfinder Bolivia staff members reviewed the proposals and their suggestions were incorporated in the final versions.

Agreements with directors of each hospital: Meetings were held with the directors of each hospital to present research proposals. They all expressed support for their implementation and appointed the official members of the research teams, as follows:

Table 2

Members of the Research Teams in Each Participating Hospital

\begin{tabular}{|c|c|c|}
\hline Hospital & Director & Research Team \\
\hline $\begin{array}{l}\text { Hospital Materno Infantil } \\
\text { Germán Urquidi, Cochabamba }\end{array}$ & $\begin{array}{l}\text { Dr. Angel Mayda } \\
\text { Terceros }\end{array}$ & $\begin{array}{l}\text { Dr. Jacqueline Severich Guardia } \\
\text { Dr. Angel Maida Terceros } \\
\text { Dr. Patricia Alcocer Soria } \\
\text { Dr. Antonio Pardo Novak }\end{array}$ \\
\hline $\begin{array}{l}\text { Hospital Alfonso Gumucio } \\
\text { Reyes, Montero }\end{array}$ & Dr. Julio Vaca & $\begin{array}{l}\text { Dr. Dafné Delgadillo } \\
\text { Dr. Gaby Orellana }\end{array}$ \\
\hline $\begin{array}{l}\text { Hospital Universitario Percy } \\
\text { Boland, Santa Cruz }\end{array}$ & Dr. Beatriz Durán & $\begin{array}{l}\text { Dr. Edgar Caballero } \\
\text { Dr. Alfredo Padilla }\end{array}$ \\
\hline
\end{tabular}

Development of data collection instruments: To speed up the process, draft data collection instruments for each study were developed in La Paz by the FRONTIERS project monitors, and the research teams in each hospital produced their final versions. The data collection instruments were based on Pathfinder's supervision checklists and materials, and on the instruments developed as part of the OR project conducted in the first stage of this study. Table 3 describes the instruments that were developed. 
Table 3

Data Collection Instruments Developed for Each Project

\begin{tabular}{|l|l|}
\hline \multicolumn{1}{|c|}{ Hospital } & \multicolumn{1}{c|}{ Instruments } \\
\hline $\begin{array}{l}\text { Hospital Materno Infantil Germán } \\
\text { Urquidi, Cochabamba }\end{array}$ & $\begin{array}{l}\text { Referral card } \\
\text { User interviews (unmet need) } \\
\text { Informed consent } \\
\text { "Number of PAC users" form } \\
\text { "Characteristics of PAC users" form }\end{array}$ \\
\hline $\begin{array}{l}\text { Hospital Alfonso Gumucio Reyes, } \\
\text { Montero }\end{array}$ & $\begin{array}{l}\text { Follow-up visit card } \\
\text { User interviews (unmet need) } \\
\text { Informed consent } \\
\text { "Number of PAC users" form } \\
\text { "Characteristics of PAC users" form }\end{array}$ \\
\hline Hospital Universitario Percy & $\begin{array}{l}\text { User exit interviews (unmet and met needs) } \\
\text { Boland, Santa Cruz }\end{array}$ \\
$\begin{array}{l}\text { Informed consent } \\
\text { Checklist } \\
\text { "Number of PAC users" form } \\
\text { "Characteristics of PAC users" form }\end{array}$ \\
\hline
\end{tabular}

Each instrument had a pre-test phase and was tailored to each situation before being applied. A joint Population Council and Pathfinder team provided technical assistance for these activities.

Coordination during the initial period of research: Each local research team hired personnel to conduct activities such as interviewing and other data collection, creating databases and entering data. FRONTIERS staff members also provided instructions for resource management, specifying what would be purchased, and the forms that would be used as receipts, among others.

\subsection{Training}

Training was provided in workshops and during on-site monitoring and TA visits. Three service providers from each of the eight hospitals that participated in the peer-review project attended the first workshop. All the participants were physicians and nurses on the ObGyn ward. In the first part of the workshop, Pathfinder staff presented the results of the peer-review project conducted in 2002, which participants then discussed and analyzed. In the second part of the workshop, FRONTIERS staff provided guidelines to write OR proposals. Each team identified remaining service delivery problems and interventions that could be tested in their hospitals, and wrote draft OR proposals. After the workshop, staff from FRONTIERS (Fernando Gonzales and Patricia Riveros) and Pathfinder (José del Barco, Medical Director) reviewed the eight draft proposals and selected four for further development. The main criteria for selection were quality and the feasibility of implementing the solutions. As mentioned, the Corea Hospital team 
members decided to withdraw from the project before the baseline data collection activities were implemented.

In the second workshop, the team members of the four selected projects learned to use EpiInfo, a free-use statistical software program developed by CDC Atlanta, to prepare their project databases. Each team used the data collection instruments they had developed before the project. FRONTIERS staff members facilitated the workshop. The workshop agendas are presented as Appendix 4.

The FRONTIERS project monitors provided on-site technical assistance and training to each team's hospital staff members in the development of data collection instruments, data entry, interviewing and observation techniques, and data analysis. At the end of each project, the monitors visited the hospitals to discuss the preliminary results, suggest additional analyses and help them prepare an outline of the final report. Once draft final reports were prepared, the FRONTIERS staff conducted additional analyses and edited the reports, which were then discussed with the research teams in order to include their observations.

\subsection{Level of Effort}

The FRONTIERS Country Advisor devoted an average of four days per month to this project. A consultant provided 60 days of technical assistance for 10 months, or an average of 6 days per month. In addition, two Pathfinder staff members provided technical assistance to implement the interventions during their routine monitoring visits.

\section{RESULTS}

In this section we present a summary of the final report of each study. The complete Spanish language final reports can be found in Appendices $1-3$.

\section{Hospital Materno Infantil Germán Urquidi, Cochabamba}

The staff of the Germán Urquidi Hospital identified the lack of linkages between emergency care and other outpatient sexual and reproductive health services, including contraception, as the main PAC service delivery problem. The research team members noticed that PAC clients were given an "Appointment and I.D. card" at the time of discharge from the hospital and that the record system used this card only to obtain data on the quantity of users cared for. The research team conducted an operations research study to test the use of this same card to link emergency services to other outpatient sexual and reproductive health services. The aim of this study was to develop a model for integral postabortion care, so that women could seek different services, including contraception, according to their specific sexual and reproductive health needs. 
The intervention included the following activities:

- Distribution and training in the use of referral cards to PAC clients at preestablished locations, such as statistics and emergency services.

- Postabortion contraception and counseling training workshop for all ObGyn residents and medicine interns, given by members of the local research team with the technical assistance from Pathfinder.

- Development of a flowchart showing the user's path through the hospital when receiving postabortion care.

Results showed that the referral card was not systematically used. Although clients were routinely referred to outpatient services, providers seldom specified the type of service required by the client. The service most women were referred to was the Pap smear.

The review of the clinical histories suggested that all users received contraceptive counseling during the three stages of the OR project (pre-intervention, intervention and post-intervention). However, the results of the exit interviews contradicted the clinical records. According to these records, only 15 percent had received counseling during the pre-intervention period, with an increase during the intervention to 93 percent and 92 percent during the post-intervention period.

In the pre-intervention stage, the proportion of women attending PAC services that left with a contraceptive method before discharge from the hospital was negligible (1\%). This proportion increased during the intervention (33\%) and post-intervention periods $(38 \%)$. The rate of return of users for follow-up visits had a similar pattern. During the follow-up visit, a gradual increase could be observed in the percentage of women that received contraceptive counseling (from $48.5 \%$ to $63.1 \%$ ), but the number of women that accepted methods remained the same $(33 \%)$. The only additional reproductive health service provided was the Pap smear.

In terms of the general characteristics of users interviewed, the average age was 26.6 years; 76 percent were living together in consensual unions; 39 percent had primary studies, 38 percent secondary studies, 16 percent higher studies and only 6 percent had no schooling at all. Twenty-nine percent of women were new mothers and 71 percent had one or more children. Of considerable concern, 43 percent got pregnant while using a contraceptive method.

In terms of unmet need for contraception, it was observed that in the pre-intervention period, 68 women did not wish to get pregnant and wanted to use a method. However, 67 of these did not receive a method; therefore, unmet need for contraception was 98 percent. During the intervention, unmet need for contraception decreased to 56 percent and during the post-intervention it declined slightly to 54 percent.

Although health providers accepted the internal referral card well, it was not widely used as proposed in the research protocol. Most providers did not systematically detect user 
needs or offer additional services beyond those that motivated the visit. Therefore, the intervention had a modest effect in establishing integrated postabortion care.

\section{Hospital Alfonso Gumucio Reyes, Montero}

One of the problems identified in the 2002 OR study was deficient communication between emergency PAC services and outpatient services in public hospitals in Bolivia. As a result, patients seldom were given information on the services they received during their hospital stay or were advised to return for other services, such as contraception.

The Alfonso Gumucio Reyes Hospital implemented an OR study to link emergency care to outpatient visits by means of a referral and follow-up visit card. The card was given to all women admitted to the hospital diagnosed with a hemorrhage in the first half of their pregnancy. The study used a non-experimental design, with before and after measurements. During the study, the number of women that returned for a follow-up visit was registered, as well as the number of new users of contraceptive methods and other reproductive health services provided in the emergency ward and outpatient offices. Exit interviews were also conducted with a sample of program users.

During the intervention phase, the following activities were carried out:

- Information and training meeting on PAC for all hospital service providers and administrative personnel.

- Distribution of referral cards to outpatient services by PAC clients at hospital admission.

- Training of providers to fill out referral card.

The average age of users was 25.8 years; 64 percent were living in consensual union with their partners, and 16 percent were married. About 16 percent of women had the abortion during their first pregnancy, and 23 percent during their second pregnancy. Two-thirds had had an abortion before, and 25 percent had had an abortion or miscarriage twice before. Nearly half the women in the sample became pregnant while using a contraceptive method; 28 percent using the rhythm method, 23 percent DMPA, 16 percent the pill and smaller proportions using other methods.

During the pre-intervention period, the rate of return for follow-up visits was 5 percent, whereas during the post-intervention period the rate of return was 18 percent, which corresponded to 27 users that returned within 7 days to an outpatient visit, of which 18 $(67 \%)$ received a contraceptive method in the outpatient visit.

In conclusion, the use of a referral card linked to an incentive (for example, in this case, they did not have to wait to be seen), increased the number of users that returned for the follow-up visit and had an important effect on diminishing the unmet need for contraception. However, the levels were not high enough to consider the intervention a success, although the rate of return increased by more than $300 \%$, still less that one-fifth of users returned for their follow-up visit. 
The most notable change between the pre and post-intervention was the increase in the proportion of women that received counseling on contraceptive methods during their hospital stay for emergency care. However, during the same period, a decrease was observed in the percentage of women that received their method of choice before discharge from the hospital.

Although few users returned for their follow-up visit, this visit has a high impact on the use of contraceptive methods. Due to the low rate of return, the hospital stay continues to be the most important moment to provide contraceptive methods to women that have decided to use them; therefore, the offer and delivery of methods should not be postponed for a later visit. Taking into account the findings of this study, the hospital should test new strategies to increase the rate of user return.

Finally, a problem was detected in the implementation of the project; namely, the high level of dependence that interventions have on the main researcher. When the researcher stops supervising the study, activities are not carried out or are not satisfactorily accomplished. This problem affects the possibilities for institutionalization and sustainability of strategies.

\section{Hospital Universitario Percy Boland, Santa Cruz}

Between March and October 2004, an operations research study was carried out at the Hospital Universitario Percy Boland in the city of Santa Cruz. A study conducted with Pathfinder Catalyst in 2002 showed that 24 percent of women attended at the hospital for PAC had unmet need for contraception at the time of discharge from the hospital. When this problem was explored with PAC service providers, they attributed this to deficient contraceptive counseling, since this task was routinely delegated to medical interns (i.e. students in their last year who work at the ObGyn ward during ten-week rotations), who did not have the skills or the knowledge to provide this service. The doctors and nurses who were trained in this area were too busy providing other services.

A solution suggested was cyclical training (every ten weeks), followed by training observations of new interns that came to this service. Therefore, two training workshops were held simultaneously for 25 ObGyn residents and 44 medicine interns, with a total duration of 10 hours ( 2 hours daily for 5 days). The training method included active participation with theoretical and practical content. The subjects covered were abortion as a public health problem, the counseling process and contraceptive methods. Trainers were doctors and nurses from the same maternity ward. Once the workshop concluded, residents and researchers observed each intern as they delivered the service to four users on average.

Results showed that these training observations clearly improved provider skills; an average improvement of 43 percent was observed between the workshop's pre and posttests. As a consequence, the proportion of women that received contraceptive counseling increased significantly from 68 percent to 84 percent. The observations showed that the quality of contraceptive counseling also improved, which was reflected in user satisfaction. In the pre-intervention period, 56 percent said they had requested a 
contraceptive method and, of these, 67 percent received the method requested before discharge from the hospital. In the post-intervention period, 83 percent requested a method and 100 percent of these women received the method chosen before discharge from the hospital. As a consequence, the unmet need for contraception decreased from 33 percent to virtually nil.

The problems posed by this study are common to many hospitals in Bolivia that receive interns regularly. Therefore, this intervention could be used more broadly to improve programs for postabortion care to women.

\section{DISSEMINATION AND UTILIZATION}

The following activities were conducted to disseminate research findings and further the utilization of the project results:

Meeting to present pre-intervention results: These meetings were held in the Cochabamba and Montero hospitals in March and May 2004. The research team at the Percy Boland Maternity in Santa Cruz presented their baseline results during the hospital's routine clinical meetings.

In both meetings there was a significant presence of physicians, ObGyn residents, medical interns, nurses and authorities from the Departmental Health Services and from the Health District. In total, 26 persons in Montero and 61 in Cochabamba attended these meetings. The following program was developed in each meeting:

- Welcome and presentation of meeting objectives-Hospital Director.

- Introductory remarks - Dr. Fernando Gonzáles, FRONTIERS Country Advisor/ Population Council.

- Bringing PAC up to date - Dr. José Del Barco, Medical Coordinator, Pathfinder.

- How operations research is managing to improve RH - Dra. Máriel Loayza, Population Council.

- Presentation of operations research projects and pre-intervention evaluation by the Montero and Cochabamba principal investigators.

Meeting to present the final results: In February 2005, Pathfinder and FRONTIERS staff presented the final results of the projects in the cities of Montero and Santa Cruz. The meeting was attended by most service providers in the ObGyn Departments of both hospitals and by representatives of the MOH Departmental Health Services.

Utilization and institutionalization: Four months after the end of the project, the cyclical training strategy for medical interns is still being used in the Percy Boland Hospital. The universities that send their students for practical training are funding part of this training. Montero Hospital has extended the use of internal referral cards to other hospital wards. 
The hospital is using its own funds to print these cards and train service providers in their use. In Cochabamba, the Germán Urquidi Hospital was not able to institutionalize the referral cards used in the project. To date, however, the patient flowchart that was established continues to be used. Staff and counterparts will continue making presentations over the following months at other hospitals to motivate greater utilization of the results of these studies.

\section{CONCLUSIONS AND RECOMMENDATIONS}

The postabortion care program in Bolivia has achieved significant goals, especially at the normative and policy levels, as can be seen by the inclusion of this service in the Maternal Child Universal Health Insurance. Despite these accomplishments, many service delivery problems persist. The objective of these operations research projects was to improve PAC services by establishing a continuous training program for interns to improve deficient contraceptive counseling services. Also, the purpose was to provide more comprehensive PAC services in two hospitals by linking emergency PAC services with other reproductive health outpatient services by means of a referral card. The intern and resident training program implemented in the Percy Boland Hospital led to the expected results; service quality increased and new training rounds are now being implemented without the support of the project. The strategies tested to obtain more comprehensive postabortion care services were not entirely successful, with only moderate success in decreasing unmet need for contraception and for other reproductive health services.

In order to prevent leaves of absence, on-site technical assistance was provided to the staff in the three public hospitals that participated in the study. Research teams from each hospital were responsible for implementing activities; during the development of projects, they were trained in different subjects related to the research process. Unfortunately, the three projects depended on the commitment of providers/ researchers, and we observed that when they were not around, providers would not implement the interventions or would carry them out with low intensity, which was a problem for sustaining the interventions. We tried to solve this by holding frequent meetings with the hospital directors and staff to discuss the interventions and to present advances and preliminary results. However, providers seem to consider these types of projects as isolated activities that go beyond their institutional context or responsibilities, and the hospital directors do not seem to have a system to enforce the activities agreed upon. Their capacity to introduce new techniques or conduct changes to improve current systems is therefore very limited. The MOH urgently needs to develop norms, guidelines or a complete system to achieve this.

The agreement with Pathfinder Bolivia contributed substantially to the proper implementation of the interventions. Pathfinder provided the training materials and the reproductive health trainers. The aim of this project was not to strengthen Pathfinder's capacity to conduct operations research, but to collaborate in the implementation of OR studies to improve existing problems. On the other hand, one project objective was to improve the capacity of hospitals to conduct operations research. This goal was met only 
partially, as it was observed that the skills of the members of the research teams remained limited even after training. However, they did improve their knowledge of the research process and could continue to expand it by participating in future projects. Nevertheless, hospital directors should not expect their staff members to conduct activities in their free time or off-hours as a way to build greater research capacity.

Regarding the future of PAC services in Bolivia, Pathfinder and IPAS, the two organizations that have provided technical assistance to this program in current years, will conclude their activities in Bolivia in the near future. The USAID Mission, the main funding source of this program, has assigned this task to EngenderHealth, which will also provide all technical and financial assistance to maternal and reproductive health activities, thus ensuring the mid-term sustainability of the program. Since the Population Council will still conduct operations research to improve health services, the two organizations will continue testing interventions to improve these services.

As mentioned, the main challenge to institutionalize PAC services in Bolivia will be to develop a system that: 1) can help the $\mathrm{MOH}$ test interventions according to pre-existing norms, 2) can help make decisions regarding the institutionalization and scaling up of interventions, and 3) that provides mechanisms to ensure the compliance of providers with the new activities. Currently, the improvement and introduction of best practices seems to depend on the attitude of individual providers, who have little incentive to do anything beyond their current routine. Beyond that, the development of a service delivery model that responds to the integral health needs of women (including contraception), as opposed to the current emphasis on emergency treatment, as well as the decentralization of PAC services to second level hospitals, in contrast to the third level hospitals in which PAC is confined today, will remain important challenges for the future.

Other challenges that remain for the program are the acceptance of the manual vacuum aspiration technique (MVA) by service providers and the purchase of the equipment by hospital administrators. Even though administrators have the resources to do so, they prefer to invest them elsewhere because they feel that the MVA equipment is not used very extensively. Also, the sharp curettage technique currently used at their hospitals meets their needs. Even though the MOH system has received technical assistance for more than 10 years, the proportion of cases treated with MVA remains under 15 percent in large hospitals, regardless of the results of different research projects showing the greater cost-effectiveness of this approach.

The OR studies described in this report contributed to improving PAC by underlining the need to take into account other client needs, particularly contraception, instead of concentrating on emergency treatment. This focus on technique is probably a consequence of excessive clinical training of Bolivian practitioners, who believe contraceptive counseling and screening for other reproductive health needs are better taken care of by nurses and medical interns. These subjects should be included in medical and nursing school syllabi in order to confront this perception. 
APPENDICES 